\title{
Oil Returns and Volatility: The Role of Mergers and Acquisitions ${ }^{\#}$
}

\author{
Martijn Bos ${ }^{*}$, Riza Demirer ${ }^{* *}$, Rangan Gupta ${ }^{* * *}$ and Aviral Kumar Tiwari ${ }^{* * * *}$
}

\section{Highlights}

- Predictive ability of M\&A for WTI oil returns and volatility was analysed.

- Nonparametric quantile-based methodology was used.

- M\&A activity predicts power oil return and volatility.

- M\&A activity by oil firms better predictor than same by non-oil acquirers

\begin{abstract}
This paper provides a novel perspective to the oil-stock market nexus by examining the predictive ability of mergers and acquisitions (M\&A) over West Texas Intermediate (WTI) oil returns and volatility using a nonparametric quantile-based methodology. Our findings suggest that M\&A activity carries significant predictive power over oil return and volatility, while predictability displays remarkably distinct patterns across various quantiles representing normal, bull and bear market states. We also observe that M\&A activity by oil firms, i.e. both the acquiring and target firms considered active in the oil and gas (O\&G) industry, generally carries greater predictive power over both oil returns and volatility compared to $M \& A$ activity by non-oil acquirers, i.e. acquirers that have entered the $O \& G$ industry by buying an oil company. Our findings imply that M\&A activity in the O\&G industry carries valuable fundamental information regarding future expectations on oil price dynamics and should be taken into account in forecasting exercises.
\end{abstract}

Keywords: Oil Returns and Volatility; Mergers and Acquisitions; Oil \& Gas Industry; Nonparametric Quantile Causality.

JEL Codes: C22, C58, Q31.

\section{Introduction}

Crude oil is regarded as the most important commodity, given its influential role in the world economy relative to other commodities, particularly in terms of its causal effects on economic downturns (Hamilton, 1983, 2008, 2009, 2013; Elder and Serletis, 2010) and inflation (Stock and Watson, 2003). Considering the real economy, oil is indispensable for many sectors including industrials, transportation and agriculture, whether used as feedstock

\footnotetext{
\# We would like to thank two anonymous referees for many helpful comments. However, any remaining errors are solely ours.

*Email: Tilburg School of Economics and Management (TISEM), Tilburg University, Tilburg, the Netherlands. Email: jmartijnbos@ hotmail.com.

${ }^{* * *}$ Department of Economics and Finance, Southern Illinois University Edwardsville, Edwardsville, IL 620261102, USA. Email: rdemire@ siue.edu.

*** Corresponding author. Department of Economics, University of Pretoria, Pretoria, 0002, South Africa; IPAG Business School, Paris, France. Email: rangan.gupta@up.ac.za.

${ }^{* * * *}$ Center for Energy and Sustainable Development (CESD), Montpellier Business School, Montpellier, France. Email: a.tiwari@montpellier-bs.com.
} 
in production or as a surface fuel in consumption (Mensi, et al., 2014a). Moreover, oil market fluctuations are widely known to spill over to other commodity markets (see for example, Kang and Yoon, 2013; Kang et al., 2016, 2017; Mensi, et al., 2013, 2014b, 2015a) as well as financial markets (see for example, Balcilar and Ozdemir, 2013; Balcilar et al., 2015, 2017b; Kang et al., 2016; Mensi et al., 2015b; Narayan and Gupta, 2015; Gupta and Wohar, 2017). Recent evidence also suggests that oil returns and volatility even have predictive power over stock market anomalies driven by informational inefficiencies (Chen et al., 2017). Given these considerations, the factors that drive return and volatility dynamics of crude oil are of paramount importance to investors, policymakers as well as academics. Naturally, there is a large literature dealing with possible macroeconomic, financial and policy-related variables that predict returns and volatility in the crude oil market (see for example, Baumeister and Kilian, 2014, 2015; Baumeister et al., 2014, 2015; Bekiros et al., 2015; Balcilar et al., 2017a; Bonaccolto et al., forthcoming).

This paper examines the predictability of oil return and volatility from a novel perspective by exploring the role of mergers and acquisitions (M\&A) activity in the oil and gas industry as a potential predictor. The strand of the finance literature on M\&A offers ample evidence on the effect of mergers on subsequent returns and volatility experienced by both the acquiring and target firms. While earlier findings in Jensen and Ruback (1983) and Jarrell et al. (1988) show that mergers seem to create value for shareholders overall, numerous studies including Agrawal et al. (1992), Loughran and Vijh (1997) and Rau and Vermaelen (1998) document evidence of a post-merger drift in which stock of acquiring firms generally underperform following acquisitions, suggesting some degree of return predictability following M\&A activity. ${ }^{1}$

Examining the role of M\&A activity on return volatility, the evidence in Langetieg et

\footnotetext{
${ }^{1}$ See Andrade et al. (2001) for a review of the literature on mergers.
} 
al. (1980), Jayaraman et al. (1991), Levy and Yoder (1993), Smith et al. (1997), Bharath and Wu (2005) and Gero and Kamerschen (2008) generally points to a statistically significant increase in return volatility due to M\&A activity, while Gero and Kamerschen (2008) relate the increase in return volatility to integration risk and uncertainty about the extent to which efficiency gains are realized via mergers. All of these studies, however, have focused on the effect of M\&A activity on the stock return dynamics for the target and the acquiring firms, without exploring its effect on the underlying product (or commodity) that drives profits in these firms' operations. To that end, the oil and gas $(\mathrm{O} \& \mathrm{G})$ industry presents a unique setup to explore the interaction between M\&A activity in this industry and price dynamics in the underlying commodity, i.e. crude oil.

In a recent study that focuses on the M\&A activity in the O\&G industry in the U.S., Hsu et al. (2017) argue that M\&A activities in the O\&G industry has momentum building periods, i.e. occur in waves, and show that M\&A is largely driven by industry-specific factors than general economic conditions. Given this finding by Hsu et al. (2017) coupled with the empirical features of M\&A activity and the evidence on its effect on stock return and volatility, one can argue that a similar link exists between M\&A activity in the O\&G industry and oil price dynamics. Motivated by these empirical findings, this paper provides a novel perspective to the oil-stock market nexus by analysing, for the first time, the role of M\&A activity in the oil industry in predicting returns and volatility of the West Texas Intermediate (WTI) oil price over the monthly period of 1978:01 to 2016:12.

Intuitively, drawing on the empirical evidence from the literature on M\&A and stock market movements, a possible link between M\&A activity in the $O \& G$ industry and oil return and volatility can be established via several possible channel(s). If, as Mitchell and Mulherin (1996) suggest, mergers occur in waves reflecting cyclicality in industry fundamentals, then one can argue that M\&A activity reflects expansionary (or recessionary) expectations in the 
O\&G industry, which can also affect the return dynamics in oil as the underlying commodity. Furthermore, if M\&A activity leads to productivity gains when demand is high and cost reductions during periods of low demand, as Dimopoulos and Sacchetto (2017) argue, then one can argue that merger options stabilize the price of the underlying product while it reduces productions costs, thus creating a new channel of impact on oil return and volatility. Finally, considering M\&A activity as a type of investment driven by real options faced by firms, greater expected volatility in oil returns increase the value of the real options associated with M\&As, linking the growth in the M\&A activity to expectations of volatility in the oil market from a real option perspective. To that end, M\&A activity dynamics can be linked to oil price dynamics via various channels and this paper provides the initial empirical evidence in that regard.

In our empirical application, we conduct the predictability analysis based on the $k$-th order nonparametric causality-in-quantiles test recently developed by Balcilar et al. (2017a). This test studies higher order causality over the entire conditional distribution and is inherently based on a nonlinear dependence structure between the variables of interest, as captured by data-driven nonparametric functions. ${ }^{2}$ It must be noted that the predictability analysis employed in our empirical application relies on a causality-based framework rather than a predictive regression approach to avoid the possible endogeneity of M\&A, given the recent findings by Monge et al., (2016, 2017), and Bos (2016) that M\&A activities are affected by both oil prices and volatility. Our findings suggest that M\&A activity carries significant predictive power over oil return and volatility, while predictability displays remarkably distinct patterns across various quantiles representing normal, bull and bear market states. We also observe that M\&A activity by oil firms, i.e. both the acquiring and

\footnotetext{
${ }^{2}$ As indicated by Balcilar et al. (2017a), the causality-in-quantile approach has the following novelties: Firstly, it is robust to misspecification errors as it detects the underlying dependence structure between the examined time series based on a nonparametric approach. Secondly, via this methodology, we are able to test for not only causality-in-mean $\left(1^{\text {st }}\right.$ moment $)$, but also causality that may exist in the tails of the distribution of the variables. Finally, we are also able to investigate causality-in-variance, thus, study higher-order dependency.
} 
target firms considered active in the $O \& G$ industry, generally carries greater predictive power over both oil returns and volatility compared to M\&A activity by non-oil acquirers, i.e. acquirers that have entered the O\&G industry by buying an oil company. Nevertheless, our findings suggest that $M \& A$ activity in the $O \& G$ industry carries significant information related to future expectations on oil price dynamics.

The rest of this paper is organized as follows: Section 2 describes the econometric framework involving the higher-moment nonparametric causality-in-quantiles test. Section 3 presents the data while Section 4 discusses the empirical results. Finally, Section 5 concludes.

\section{Econometric Framework}

In this section, we briefly present the methodology for the detection of nonlinear causality via a hybrid approach as developed by Balcilar et al. (2017a), which in turn is based on the frameworks of Nishiyama et al. (2011) and Jeong et al. (2012). We start by denoting oil returns by $y_{t}$ and the predictor variable (in our case, measure of M\&A activity - discussed in detail in the next section) as $x_{t}$. Defining $Y_{t-1} \equiv\left(y_{t-1}, \ldots, y_{t-p}\right), X_{t-1} \equiv\left(x_{t-1}, \ldots, x_{t-p}\right)$ and $Z_{t}=\left(X_{t}, Y_{t}\right)$, let $F_{y_{t} \mid Z_{t-1}}\left(y_{t}, Z_{t-1}\right)$ and $F_{y_{t} \mid Y_{t-1}}\left(y_{t}, Y_{t-1}\right)$ denote the conditional distribution functions of $y_{t}$ given $Z_{t-1}$ and $Y_{t-1}$, respectively. If we denote $Q_{\theta}\left(Z_{t-1}\right) \equiv Q_{\theta}\left(y_{t} \mid Z_{t-1}\right)$ and $Q_{\theta}\left(Y_{t-1}\right) \equiv Q_{\theta}\left(y_{t} \mid Y_{t-1}\right)$, we obtain $F_{y_{t} \mid Z_{t-1}}\left\{Q_{\theta}\left(Z_{t-1}\right) \mid Z_{t-1}\right\}=\theta$ with probability one. As a result, the (non)causality in the -th quantile hypotheses to be tested are defined as:

$$
\begin{aligned}
& H_{0}: P\left\{F_{y_{t} \mid Z_{t 1}}\left\{Q\left(Y_{t 1}\right) \mid Z_{t 1}\right\}=\right\}=1, \\
& H_{1}: \quad P\left\{F_{y_{t} \mid Z_{t 1}}\left\{Q\left(Y_{t 1}\right) \mid Z_{t 1}\right\}=\right\}<1 .
\end{aligned}
$$

Jeong et al. (2012) use the distance measure $J=\left\{\varepsilon_{t} E\left(\varepsilon_{t} \mid Z_{t-1}\right) f_{z}\left(Z_{t-1}\right)\right\}$, where $\varepsilon_{t}$ is the regression error term and $f_{z}\left(Z_{t-1}\right)$ is the marginal density function of $Z_{t-1}$. The regression 
error $\varepsilon_{t}$ emerges based on the null hypothesis in (1), which can only be true if and only if $E\left[1\left\{y_{t} \leq Q_{\theta}\left(Y_{t-1}\right) \mid Z_{t-1}\right\}\right]=\theta$ or, expressed in a different way, $1\left\{y_{t} \leq Q_{\theta}\left(Y_{t-1}\right)\right\}=\theta+\varepsilon_{t}$, where $\mathbf{1}\{\Varangle$ is the indicator function. Jeong et al. (2012) show that the feasible kernel-based sample analogue of $J$ has the following format:

$$
\hat{J}_{T}=\frac{1}{T\left(\begin{array}{ll}
T & 1
\end{array}\right) h^{2 p}} \sum_{t=p+1}^{T} \sum_{s=p+1, s \neq t}^{T} K\left(\frac{Z_{t 1} Z_{s 1}}{h}\right) \hat{t} .
$$

where $K(\cdot)$ is the kernel function with bandwidth $h, T$ is the sample size, $p$ is the lag order, and ${ }^{\wedge}$ is the estimate of the unknown regression error, which is given by

$$
\hat{t_{t}}=1\left\{y_{t} Q\left(Y_{t 1}\right)\right\} \quad .
$$

In this specification, $\hat{Q}_{\theta}\left(Y_{t-1}\right)$ is an estimate of the $\theta^{\text {th }}$ conditional quantile of $y_{t}$ given $Y_{t-1}$, and we estimate $\hat{Q}_{\theta}\left(Y_{t-1}\right)$ using the nonparametric kernel method as

$$
\hat{Q}_{\theta}\left(Y_{t-1}\right)=\hat{F}_{y_{t} \mid Y_{t-1}}^{-1}\left(\theta \mid Y_{t-1}\right)
$$

where $\hat{F}_{y_{t} \mid Y_{t-1}}\left(y_{t} \mid Y_{t-1}\right)$ is the Nadarya-Watson kernel estimator given by

$$
\hat{F}_{y_{t} \mid Y_{t 1}}\left(y_{t} \mid Y_{t 1}\right)=\frac{{ }_{s=p+1, s t}^{T} L\left(\left(\begin{array}{ll}
Y_{t 1} & \left.Y_{s 1}\right) / h
\end{array}\right) 1\left(\begin{array}{ll}
y_{s} & y_{t}
\end{array}\right)\right.}{T},
$$

with $L(\cdot)$ denoting the kernel function and $h$ the bandwidth.

As an extension of Jeong et al. (2012)'s framework, Balcilar et al. (2017a) develop a test for the second moment which allows us to test the causality between M\&A activity and oil return volatility. Adapting the approach in Nishiyama et al. (2011), higher order quantile causality can be specified in terms of the following hypotheses formulated as:

$$
\begin{array}{ll}
H_{0}: P\left\{F_{y_{t}^{k} \mid Z_{t 1}}\left\{Q\left(Y_{t 1}\right) \mid Z_{t 1}\right\}=\right\}=1 \quad \text { for } k=1,2, \ldots, K \\
H_{1}: P\left\{F_{y_{t}^{k} \mid Z_{t 1}}\left\{Q\left(Y_{t 1}\right) \mid Z_{t 1}\right\}=\right\}<1 \quad \text { for } k=1,2, \ldots, K
\end{array}
$$


We integrate the entire framework and test whether $x_{t}$ Granger causes $y_{t}$ in quantile $\theta$ up to the $k^{\text {th }}$ moment using Eq. (7) to construct the test statistic in Eq. (6) for each $k$. The causality-in-variance test is then calculated by replacing $y_{t}$ in Eqs. (3) and (4) with $y_{t}^{2}$ measuring the volatility of oil returns. However, one can show that it is difficult to combine the different statistics for each $k=1,2, \ldots, K$ into one statistic for the joint null in Eq. (7) because the statistics are mutually correlated (Nishiyama et al., 2011). To overcome this issue, Balcilar et al. (2017a) propose a sequential-testing method as described in Nishiyama et al. (2011). First, we test for nonparametric Granger causality in the first moment (i.e., $k=1$ ). Nevertheless, failure to reject the null for $k=1$ does not automatically lead to noncausality in the second moment. Thus, we can still construct the test for $k=2$, as discussed in detail in Balcilar et al. (2017a).

The empirical implementation of causality testing via quantiles entails specifying three key parameters: the bandwidth $(h)$, the lag order $(p)$, and the kernel type for $(K(\cdot)$ and $L(\cdot))$ $K(\cdot)$ and $L(\cdot)$. We use a lag order of $p=3$, based on the Schwarz information criterion (SIC), which is known to select a parsimonious model as compared with other lag-length selection criteria. The SIC criterion helps to overcome the issue of over-parameterization that typically arises in studies using nonparametric frameworks. ${ }^{3}$ For each quantile, we determine the bandwidth parameter $(h)$ by using the leave-one-out least-squares cross validation method. ${ }^{4}$ Finally, for $K(\cdot)$ and $L(\cdot)$, we use Gaussian kernels.

\footnotetext{
${ }^{3}$ Hurvich and Tsai (1989) examine the Akaike information criterion (AIC) and show that it is biased towards selecting an over-parameterized model, whereas the SIC is asymptotically consistent.

${ }^{4}$ For each quantile, we determine the bandwidth $h$ using the leave-one-out least-squares cross validation method of Racine and Li (2004) and Li and Racine (2004).
} 


\section{Data}

The empirical analysis utilizes monthly data for WTI oil prices and M\&A activity over the period of 1978:01 to 2016:12, i.e., 468 observations. The start and end dates are governed purely by the availability of data on M\&A activity. Oil price data is sourced from the Global Financial Database, with returns computed as the monthly logarithmic change of oil prices multiplied by 100 to convert the returns into percentages (RETURNS). Since WTI oil price data is available from 1859:09, we do not lose the first observation (month) while computing oil returns. WTI returns are plotted in Figure 1(a).

In the case of M\&A activity, two alternative measures have been proposed (Bos, 2016): (i) the sum of the transaction values associated with the takeovers in a given period; and (ii) the number of deals in a given period. In this paper, we choose the second measure as the transaction value of the merger deal is not always communicated and this measure is likely to be sensitive to large deals. The data for the number of deals (DEALS) was collected from the SDC Platinum database of Thomson Reuters. Deals were allocated to the period in which they were announced. It must, however, be noted that, between the announcement and the effective date, (i) a deal could be completed; (ii) a deal could be completed but with adjusted conditions; or (iii) a deal could be cancelled. In this paper, we only consider completed deals to measure M\&A activity. Since we do not consider transaction value, it is not important whether the deal was completed or completed after some adjustments to the conditions. Therefore, M\&A activity is measured by the number of completed M\&A transactions each month between 1978 and 2016 that involved an oil company and executed by an acquirer headquartered in the U.S. 
Figure 1(a). Monthly WTI Oil Returns.

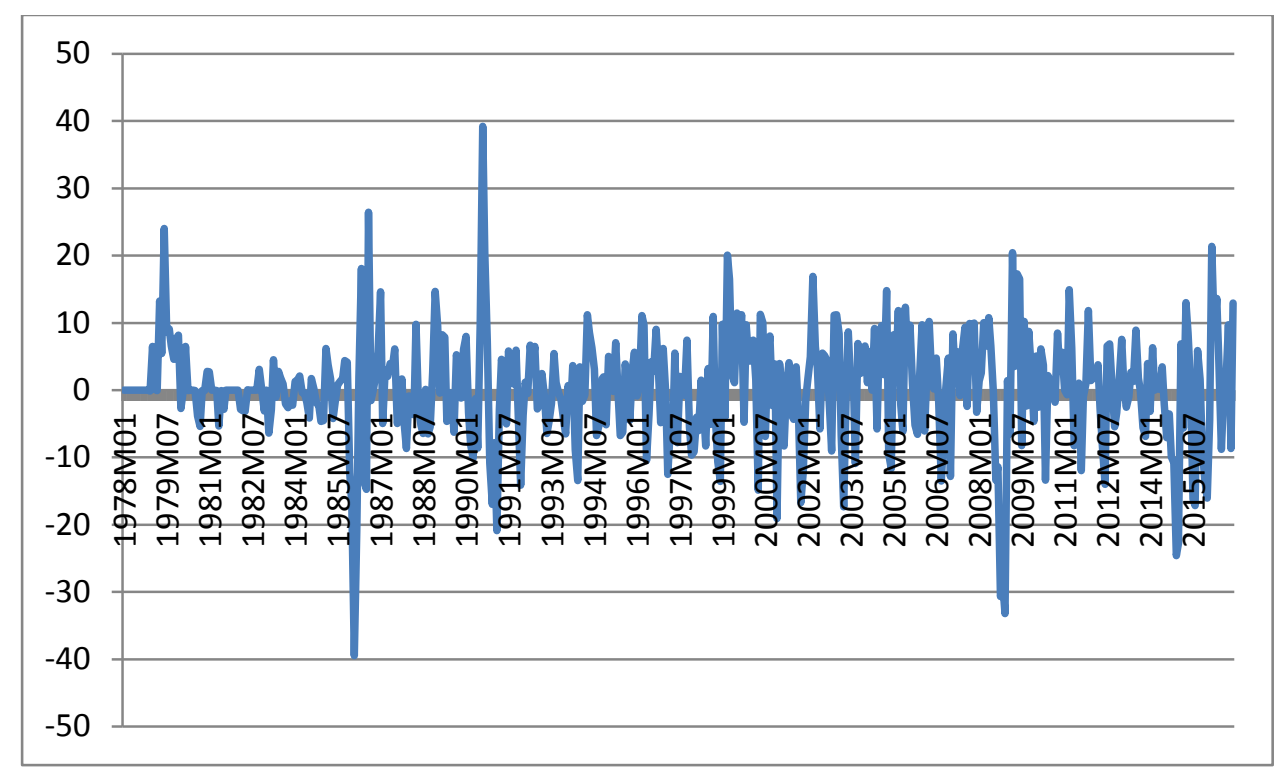

Figure 1(b). M\&A Activities.

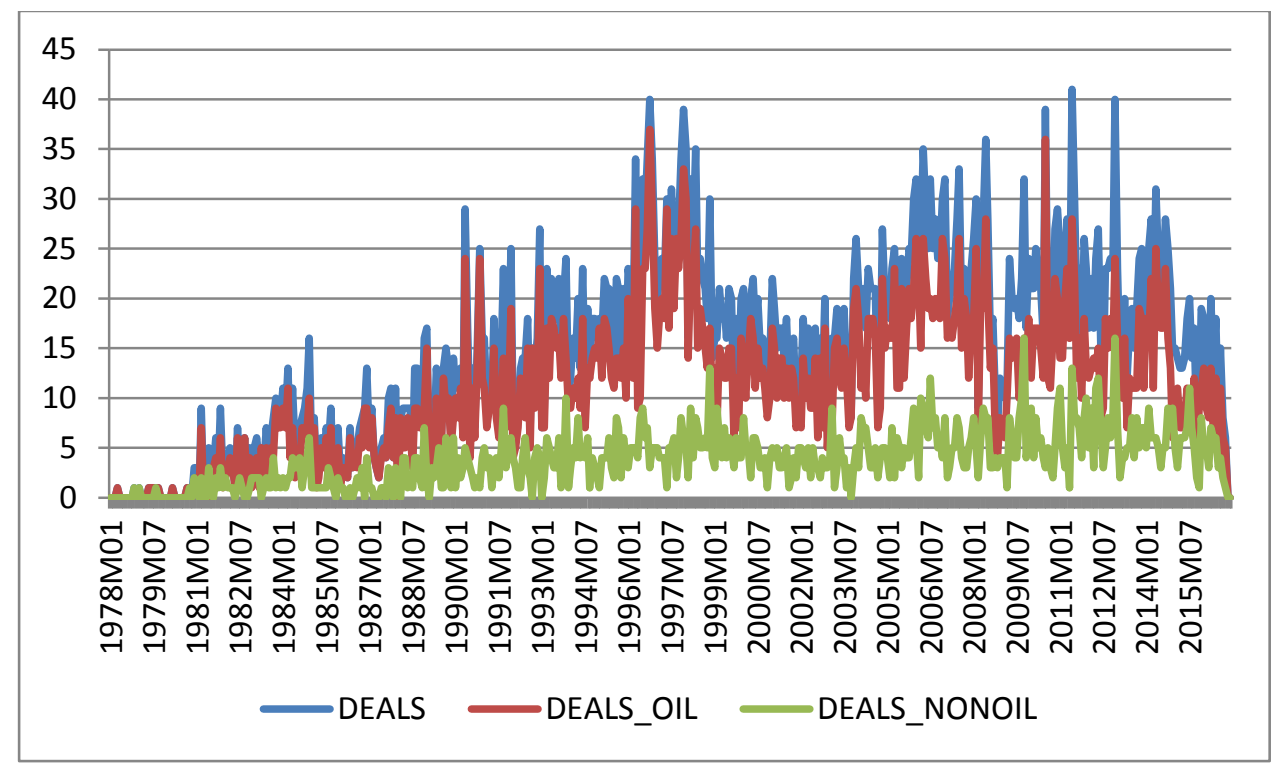

Notes: The figure plots the number of completed M\&A transactions each month (DEALS) between 1978:01 and 2016:12. DEALS_OIL represents M\&A activity by an oil acquirer, i.e., both the acquiring and target firms considered are active in the O\&G industry. DEALS_NONOIL represents the M\&A activity by a non-oil acquirer, which involves deals of acquirers that have entered the $O \& G$ industry by buying an oil company.

Figure 1(b) provides a plot of the completed deals each month. As mentioned earlier, the M\&A literature provides ample evidence that takeovers cluster over time, termed as merger 
waves, and we see in Figure 1(b) that this also holds for the U.S. O\&G industry as well, with a peak in takeovers observed in 1996 and 1998. Interestingly, the number of deals has stayed at a relatively high level since the financial crisis despite the slump in the oil market driven by economic slowdown observed globally. Dimopoulos and Sacchetto (2017) argue that mergers represent an alternative to exit for poor performers in an industry and thus firms merge in bad times to reduce costs and avoid exiting. Therefore, the relatively high level of M\&A activity observed since the financial crisis can be explained by firms' executing merger options as an alternative to exit decisions.

Besides total deals, we also analyse the role of M\&A activity by an oil acquirer (DEALS_OIL), i.e., in this case, both the acquiring and target firms considered are active in the O\&G industry. In the same vein, we also performed our tests using the M\&A activity by a non-oil acquirer (DEALS_NONOIL) as a predictor, which involves deals of acquirers that have entered the O\&G industry by buying an oil company. This could be a firm from other industries such as private equity, business service or the chemical industry. DEALS_OIL and DEALS_NONOIL have also been plotted in Figure 1(b) for easy comparison. We observe that the patterns of movements of these two variables are, in general, similar. Note that, over the period of the study, there were a total of 6,949 deals, with 5,179 of them (about $75 \%$ ) acquired by oil companies, and the remaining 1,770 acquired by non-oil companies.

Table 1 provides the summary statistics for RETURNS, DEALS_OIL and DEALS_NONOIL. We observe that oil returns are skewed to the left with excess kurtosis, while the data on the three M\&A activity measures are skewed to the right, but with excess kurtosis, which in turn, results in the null of normality under the Jarque-Bera test to be overwhelmingly rejected at the highest level of significance for RETURNS, DEALS_OIL and DEALS_NONOIL. The non-normal distributions, in turn, provide preliminary motivation for relying on a quantiles-based approach adopted in our empirical analysis. 
Table 1. Summary Statistics

\begin{tabular}{lrrrr}
\hline & \multicolumn{4}{c}{ Variable } \\
Statistic & RETURNS & DEAL & OIL & NONOIL \\
\hline Mean & 0.2677 & 14.8483 & 11.0662 & 3.7821 \\
Median & 0.1183 & 15.0000 & 11.0000 & 4.0000 \\
Maximum & 39.2189 & 41.0000 & 37.0000 & 16.0000 \\
Minimum & -39.4190 & 0.0000 & 0.0000 & 0.0000 \\
Std. Dev. & 8.1363 & 9.1042 & 7.2026 & 2.8177 \\
Skewness & -0.3879 & 0.2241 & 0.4666 & 0.8387 \\
Kurtosis & 6.3647 & 2.5283 & 3.0008 & 4.0653 \\
Jarque-Bera & 232.5017 & 8.2558 & 16.9822 & 77.0002 \\
$p$-value & 0.0000 & 0.0161 & 0.0002 & 0.0000 \\
Observations & \multicolumn{4}{c}{468} \\
\hline
\end{tabular}

Notes: Std. Dev. stands for standard deviation. $p$-value corresponds to the Jarque-Bera test with the null of normality.

\section{Empirical Findings}

\subsection{Tests of non-linearity and structural breaks}

Before we begin our discussion of the findings from the causality-in-quantiles tests, for the sake of completeness and comparability, we first provide the findings from the standard linear Granger causality tests with the null hypothesis that the various M\&A activity variables do not affect oil returns. As shown in Table 1, the standard linear Granger causality tests yield no evidence of causality that emanates from any of the M\&A related variables (DEALS, DEALS_OIL, and DEALS_NONOIL) to oil returns. Therefore, standard linear tests imply no significant causal relationships between M\&A activity and oil returns. ${ }^{5}$

Table 2. Linear Granger Causality Test for WTI Returns.

\begin{tabular}{lll}
\hline Predictor Variable & $\chi^{2}(\mathbf{3})$-stat & $\boldsymbol{p}$-value \\
\hline DEALS & 2.6350 & 0.4514 \\
DEALS_OIL & 3.5489 & 0.3145 \\
DEALS_NONOIL & 4.2772 & 0.2330 \\
\hline
\end{tabular}

Note: The null hypothesis is that a specific M\&A activity does not affect WTI returns.

\footnotetext{
5 Interestingly, the null that RETURNS does not cause DEALS $\left(\chi^{2}(3)=8.0855, p\right.$-value $\left.=0.0443\right)$ and DEALS_OIL $\left(\chi^{2}(3)=10.6600, p\right.$-value $\left.=0.0137\right)$ could be rejected at the 5 percent level, while the null that RETURNS does not cause DEALS_NONOIL $\left(\chi^{2}(3)=2.7766, p\right.$-value $\left.=0.4274\right)$ could not be rejected even at the 10 percent level of significance. These results highlight the endogeneity of DEALS and DEALS_OIL especially and hence, motivates the use of causality-based framework rather than a predictive regression model. Complete details of these results are available upon request from the authors.
} 
Given the insignificant results obtained from linear causality tests, next we statistically examine the presence of nonlinearity in the relationship between oil returns and the predictor variables representing M\&A activities. For this purpose, we apply the Brock et al. (1996, BDS) test on the residuals from the various return equations used in the linear causality tests involving DEALS, DEALS_OIL and DEALS_NONOIL. The results of the BDS test of nonlinearity presented in Table 3 provide strong evidence of rejection of the null hypothesis of i.i.d. residuals at various embedded dimensions $(m)$. Thus, we conclude that there exists nonlinearity in the relationship between oil returns and the various measures of M\&A activity. This evidence also indicates that the findings based on the linear Granger causality test as presented in Table 2 cannot be deemed robust and reliable.

Table 3. Brock et al. (1996) (BDS) Test of Nonlinearity.

\begin{tabular}{llllll}
\hline & \multicolumn{5}{c}{ Dimension } \\
Predictor Variable & $\mathbf{2}$ & $\mathbf{3}$ & $\mathbf{4}$ & $\mathbf{5}$ & $\mathbf{6}$ \\
\cline { 2 - 6 } DEALS & $5.7181 * * *$ & $6.9965 * * *$ & $7.7814 * * *$ & $8.6308 * * *$ & $9.8322 * * *$ \\
DEALS_OIL & $5.6812 * * *$ & $7.0153 * * *$ & $7.7713 * * *$ & $8.5808 * * *$ & $9.8228 * * *$ \\
DEALS_NONOIL & $6.1894 * * *$ & $7.6519 * * *$ & $8.5285 * * *$ & $9.3964 * * *$ & $10.5699 * * *$ \\
\hline
\end{tabular}

Notes: The table reports the $z$-statistic of the BDS test corresponding to the null of i.i.d. residuals, with the test applied to the residuals recovered from the oil returns equation used to test linear Granger causality. *** indicates rejection of the null hypothesis at the 1 per cent level of significance.

In addition to the BDS test, we also apply the Bai and Perron (2003) tests of multiple structural breaks on the oil return equations that are used to test linear Granger causality based on the various types of M\&A activity measures. Using the powerful UDmax and/or WDmax tests, and allowing for a maximum of five breaks with fifteen percent endpoint trimming as well as heterogeneous error distributions across breaks, we detect four (1984:01, 1991:01, 2002:06, 2008:05), two (1986:04, 2007:11), and four (1985:05, 1991:03, 2002:02, 2008:03) breaks in the relationship of RETURNS with DEALS, DEALS_OIL and 
DEALS_NONOIL respectively. ${ }^{6}$ The presence of these breaks further confirms our earlier findings, based on nonlinearity tests, that the linear model is misspecified.

\subsection{Nonlinear causality tests}

Given the strong evidence of nonlinearity and regime changes in the relationship between oil returns and M\&A related measures, we now turn our attention to the causality-inquantiles test, which is robust to possible misspecification due to nonlinearity and structural breaks given its nonparametric (i.e. data-driven) structure.

Figure 2(a) and Figure 2(b) respectively, present the findings from the causality-inquantiles tests (with the null that M\&A activities do not Granger cause oil returns and volatility) estimated over the range of quantiles from 0.05 to 0.95 for RETURNS and volatility, i.e., squared RETURNS. Note that we standardize the three M\&A measures by dividing them by their respective standard deviation estimates so that we can compare the strength of predictability by the estimated test statistics across the three M\&A measures. Unlike the insignificant findings from the linear tests reported in Table 2, we observe in Figure 2(a) that the null of no-causality emanating from the M\&A activities is consistently rejected (with a peak at the quantile of 0.45 ), except at the highest quantile of 0.95 for DEALS and DEALS_OIL, and over the quantile range of 0.85 to 0.95 for DEALS_NONOIL. This suggests that all three measures of M\&A activity have significant predictive power over oil returns, with the predictive power relatively weaker during periods of extreme bullish periods represented by the highest quantiles of the conditional distribution of oil returns.

As far as the strength of predictability is concerned, we observe that DEALS is in general the strongest predictor of oil returns except for the quantile 0.10 and 0.90 , for which DEALS_OIL has the highest test statistics. DEALS_NONOIL is clearly the weakest predictor, implying that M\&A activity by an oil acquirer carries greater informational value

\footnotetext{
${ }^{6}$ Complete details of the Bai and Perron (2003) tests of structural breaks are available upon request from the authors.
} 
Figure 2(a). Causality-in-Quantiles Test Results for Oil Returns

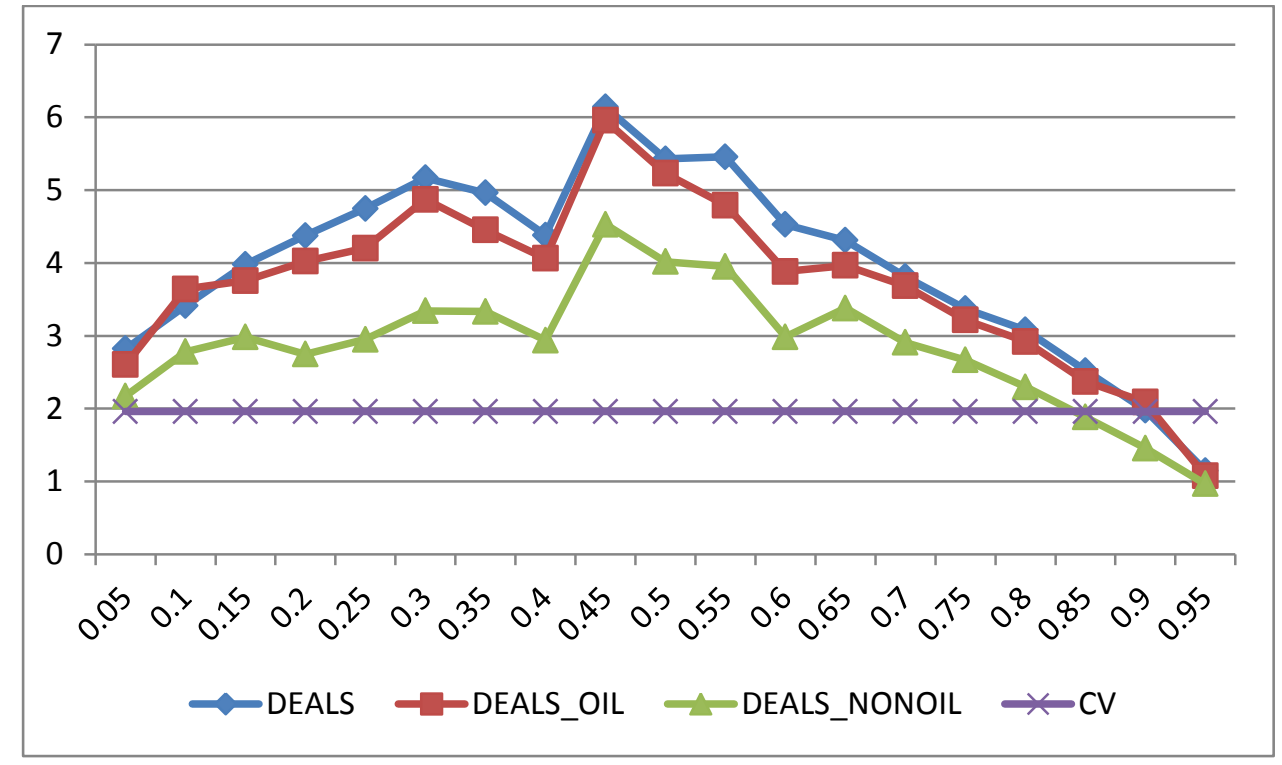

Figure 2(b). Causality-in-Quantiles Test Results for Oil Volatility (Squared Returns)

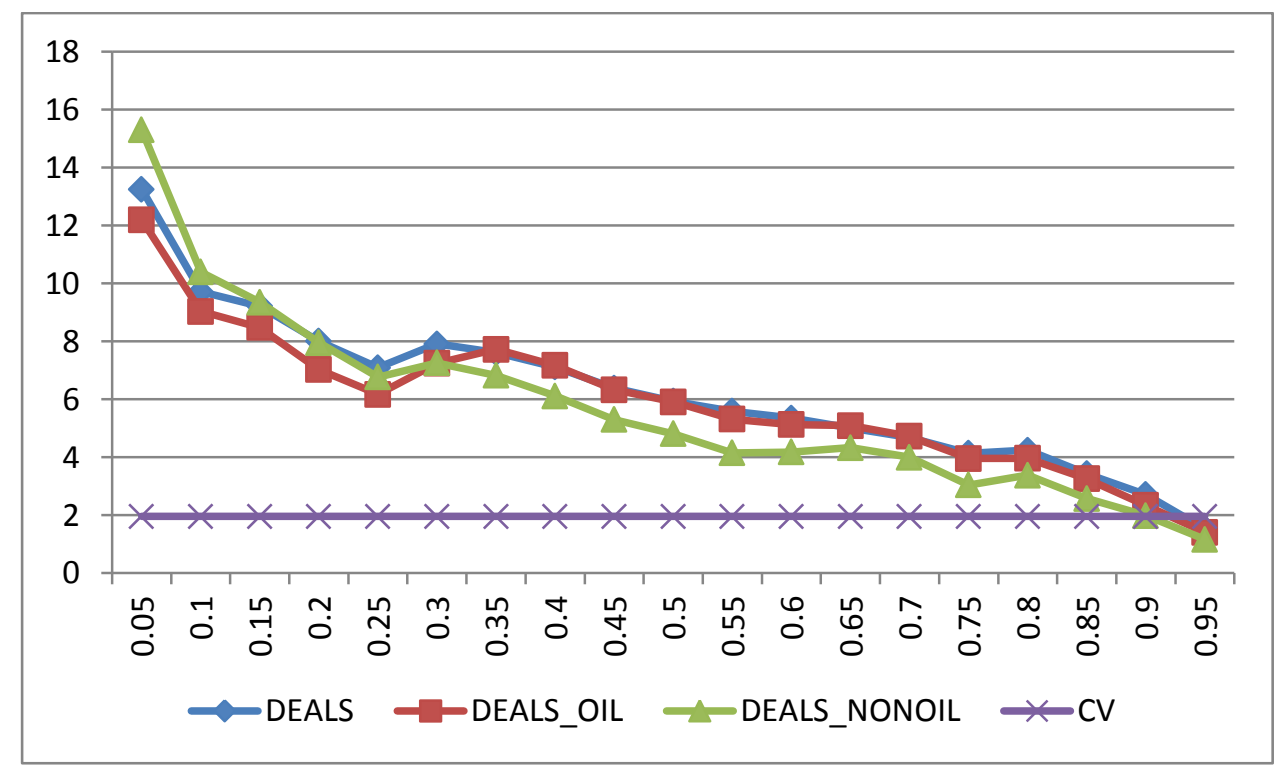

Notes: $\mathrm{CV}$ is the 5 percent critical value of 1.96 . The horizontal axis measures the various quantiles while the vertical axis captures the tests statistic value. The lines corresponding to DEALS, DEALS_OIL and DEALS_NONOIL show the rejection (non-rejection) of the null of no Granger causality from the various measures of M\&A activity measures to oil returns or volatility at the 5 percent level, if the lines are above (below) 1.96 for a specific quantile.

compared to that of a non-oil acquirer when it comes to predicting oil returns. The lack of predictability at the higher quantiles representing bullish market states may be due to the 
presence of informational inefficiencies during extreme market conditions, possibly driven by herd behaviour, such that fundamental information reflected by M\&A activity is not fully reflected in oil price dynamics. On the other hand, strong causality observed during normal market conditions, i.e. around the median of the conditional distribution, reflects a level of efficient processing of fundamental industry information by market participants during normal market states. Similarly, significant causality during bearish market states, i.e. lower quantiles, reflect firms' utilization of merger options during industry downturns as an alternative to exit decisions, thus establishing a causal link between M\&A activity and future oil returns during bearish states.

Next, we turn our attention to the impact of M\&A activities on oil return volatility, reported in Figure 2(b). Consistent with the findings for oil returns reported in Figure 2(a), barring the highest quantile of 0.95 , all three M\&A measures are found to have predictive power over oil return volatility over the remainder of the conditional distribution. Interestingly and unlike the case for oil returns, we observe the strongest predictability at the lowest quantile of 0.05 with the strength of the predictability displaying a downward trend in general across the quantile range of 0.05 to 0.95 . This finding suggests that oil volatility is most strongly predicted by M\&A activities when it is low. Considering that mergers improve productive efficiency via reallocation and synergies, it is possible that M\&A activity has a positive effect on price stability in the oil market as new entrants' average productivity exceeds that of incumbents. This argument is further supported by the observation that the strongest predictor of volatility over the quantile range of 0.05 to 0.15 happens to be DEALS_NONOIL, representing deals of non-oil acquirers like private equity or firms from other industries that have entered the O\&G industry by buying an oil company. To that end, the strong predictive power of non-oil acquisition deals over oil return volatility at the extreme low quantiles reflects improved productive efficiencies offered by non-oil firms 
entering into the O\&G industry. In the case of the remaining quantiles, however, we observe that M\&A activity by an oil acquirer (DEAL_OIL) serves as the strongest predictor of oil return volatility, consistent with the evidence for oil returns in Figure 2(a). Overall, our findings suggest that M\&A activity carries significant predictive power over oil return and volatility, while predictability displays remarkably distinct patterns across various quantiles representing normal, bull and bear market states and also depending on the nature of the acquiring firm involved in the transaction.

At this point, it must be noted that despite the robust inferences derived from the causality-in-quantiles tests, it would also be interesting to estimate the magnitude and direction of the effects of M\&A on oil market movements at various quantiles. However, in a nonparametric framework, this is not straightforward. To do so, one will need to employ the first-order partial derivative. Estimation of the partial derivatives for nonparametric models can experience complications because nonparametric methods exhibit slow convergence rates, which can depend on the dimensionality and smoothness of the underlying conditional expectation function. What one could however do is to look at a statistic that summarizes the overall effect or the global curvature (i.e., the global sign and magnitude), but not the entire derivative curve. In this regard, a natural measure of the global curvature is the average derivative $(\mathrm{AD})$. One could use the conditional pivotal quantile, based on approximation or the coupling approach of Belloni et al., (2017), to estimate the partial ADs. The pivotal coupling approach additionally can approximate the distribution of $\mathrm{AD}$ using Monte Carlo simulation. Given that in our case, the focus is on predictability of the oil market movements, and not necessarily on the sign (direction) of the effect at this stage, we leave this for future research. ${ }^{7}$

\footnotetext{
${ }^{7}$ However, even though we cannot draw one-to-one correspondence between standard quantile regressions and our nonparametric causality-in-quantiles test, preliminary evidence tends to suggest that M\&A activities is associated with lower oil returns and greater return volatility. Complete details of these results are available upon request from the authors.
} 


\subsection{Additional results}

In this subsection, based on the suggestions of an anonymous referee, we conduct three additional analysis and report results in the Appendix of the paper. ${ }^{8}$

(1) First, in Table A1 we present the results from a $\operatorname{GARCH}(1,1)$ model, with the first lag of DEALS, DEALS_OIL, and DEALS_NONOIL included in both the mean and variance equation. We observe, while these variables are significantly positive in the variance equation, they have no predictability for oil returns. However note that the impact of DEALS_OIL is only significant at the 10 percent level of significance;

(2) Second, we derive the conditional volatility of oil returns from a $\operatorname{GARCH}(1,1)$ model and then use the derived variance to run the causality-in-quantiles test for volatility. As can be seen from Figure A1, there is no evidence of predictability at any quantile for volatility as derived from DEALS, DEALS_OIL, and DEALS_NONOIL, unlike to what was observed for squared returns;

(3) Finally, we also obtain a model-free based measure of volatility, namely realized volatility (RV), which in turn is derived via daily data obtained from the Global Financial Database. Following the extant literature, RV is computed as the sum of daily squared returns over a specific month. In Figure A2, we present the causality-in quantiles results for the predictability of RV derived from DEALS, DEALS_OIL, and DEALS_NONOIL. As can be seen, predictability is observed for DEALS and DEALS_OIL over the quantile range of 0.20 to 0.75 , while that of DEALS_NONOIL is only restricted to the quantile range of $0.30-0.35$. The peak of predictability is achieved at the quantile 0.30 .

\footnotetext{
${ }^{8}$ We thank an anonymous referee for these suggestions.
} 
When we compare the results obtained from the causality-in-quantiles test with that of the conditional mean-based $\operatorname{GARCH}(1,1)$ model, we clearly see the advantage of using a quantiles based approach, especially in the case of returns, for which the $\operatorname{GARCH}(1,1)$ model shows no predictability. Examining the causality-in-quantiles test results with measures of conditional volatility derived from a $\operatorname{GARCH}(1,1)$ model and $\mathrm{RV}$, we observe marked differences in results compared to those obtained under squared returns. We see that the conditional volatility with the $\operatorname{GARCH}(1,1)$ model shows no predictability, while under RV, the same is restricted to quantiles barring the extreme one. Recall that we obtained strong evidence of predictability for squared returns, barring the upper-most quantile of 0.95 , with the peak at the lowest quantile considered, i.e., 0.05 . Note that the test developed by Balcilar et al., (2017a) is $k$-th moment test of the dependent variable. So when the dependent variable is returns, the second moment captured by the squared returns is what is traditionally defined as volatility in the extant literature. In other words, with returns as the dependent variable, the test of volatility (squared returns) follows naturally the framework developed by Balcilar et al., (2017a), i.e., the estimate of volatility used is model-free.

Volatility being a latent variable, there are large number of models that aim to capture the behaviour of volatility, which in the first place is measured by squared returns. In this regard, the GARCH-family models of conditional volatility are most well-known. An open question is, however, which GARCH model to use, as different models are aimed to capture different features of squared returns. Given this challenge, one option is to use realized volatility when high frequency data is available, which is a model free estimate of volatility. The use of realized volatility is in some sense in line with the test, which uses squared returns to capture volatility, which in turn, follows obviously from the second moment of the dependent variable (without having to estimate a specific GARCH-type 
model of conditional volatility), which in our case is oil returns. As pointed out by Balcilar et al., (2016), given what the $k$-th moment test aims to achieve, if any measure of volatility should be used besides squared returns, statistically it should be a model-free estimate, like the realized-volatility that we utilize in our analysis. Nevertheless, in terms of the robustness of the inferences, one should consider those obtained under squared returns as a measure of volatility. Given this line of reasoning, we have presented these additional results, but included them in the Appendix instead of the main text.

\section{Conclusion}

This paper provides a novel perspective to the oil-stock market nexus by examining the predictive power of mergers and acquisitions (M\&A) over returns and volatility in the WTI oil market using a $k$-th order nonparametric quantile-based methodology that allows to capture nonlinear causal effects. Using monthly data on oil returns and M\&A activities covering oil and non-oil acquirers in the oil and gas industry over the period of 1978:01 to 2016:12, we first show that standard linear causality tests yield insignificant results in terms of the predictive power of M\&A activity over WTI returns. However, additional tests reveal strong evidence of nonlinearity and regime changes in the relationship between oil returns and the various measures of M\&A activity, implying that the linear Granger causality test is misspecified, thus the results cannot be relied on.

Applying the nonparametric quantile-causality test, which is robust to misspecification due to nonlinearity and structural breaks, we show that M\&A activities possess significant predictive power over oil return and volatility, while predictability displays remarkably distinct patterns across various quantiles representing normal, bull and bear market states. Barring the highest quantiles of the conditional distribution of oil returns and volatility, we observe strong causal effects particularly at the median and lowest quantiles of the respective 
conditional distributions of returns and volatility. We also observe that M\&A activity by oil firms, i.e. both the acquiring and target firms considered active in the oil and gas (O\&G) industry, generally carries greater predictive power over both oil returns and volatility compared to M\&A activity by non-oil acquirers, i.e. acquirers that have entered the $O \& G$ industry by buying an oil company. Overall, our findings imply that M\&A activity in the O\&G industry carries valuable fundamental information regarding future expectations on oil price dynamics.

From the perspective of an academic, our results tend to suggest that the WTI market cannot be categorized as weakly efficient based on the information content of M\&A activities, barring the higher quantiles. From an investor's perspective, with the exception of bullish oil market state with high level of volatility, measures of M\&A activity can be used for forecasting and/or portfolio allocation purposes in order to improve risk/return tradeoffs. Finally, from a policy making perspective, the evidence of strong predictive power of M\&A activities over crude oil return and volatility suggests that policy makers who are worried about the potential negative impact of oil price fluctuations on the real economy should take into account measures of M\&A activity in their oil forecasting models. However, it must be noted that nonlinearity and possible structural breaks must be taken into account in order to correctly capture the effect of M\&A activity on oil returns, as our results show that using a linear model is likely to lead to incorrect inferences. Hence, in general, our results highlight the importance of testing for nonlinearity and structural changes, and if it exists, use a datadriven nonlinear approach to analyze causal relationships. The results also highlight the importance of having a nonlinear pricing framework that integrates M\&A activities in the pricing model, perhaps via models that utilize higher order moments.

As part of future research, it would be interesting to extend our analysis to a forecasting exercise, as in Bonaccolto et al., (forthcoming), since in-sample predictability does not 
guarantee the same over- and out-of-sample. Also, as pointed out by an anonymous referee, our approach is bivariate, similar to those of Nishiyama et al. (2011) and Jeong et al. (2012) upon which we build our econometric model. However, as discussed in the related literature cited in the introduction, considering that both the oil market and M\&A movements could also be affected by other possible factors, we would ideally need a multivariate model. Therefore, extending the bivariate analysis presented in this paper to a multivariate framework is also an important area of future research, which in turn, would require us to validate our finding after controlling for additional common predictors that potentially affect both M\&A activity and the oil market. However, it must be noted that, nonlinear causality tests are in general bivariate (see for example, Hiemstra and Jones (1994), and Diks and Panchenko (2005, 2006)). In recent papers, Bai et al., $(2010,2011)$ have developed a multivariate version of the nonlinear causality test, but the framework is restricted to a conditional mean-based model and analyses only causality in the first-moment, leaving out the volatility analysis.

\section{References}

Agrawal, A., Jaffe, J. F., and Mandelker, G. N. 1992. The post-merger performance of acquiring firms: A re-examination of an anomaly. The Journal of Finance, 47, 1605-1621.

Andrade, G. , Mitchell, M. , Stafford, E. , 2001. New evidence and perspectives on mergers. Journal of Economic Perspectives 15 (2), 103-120.

Bai, J., Perron, P., 2003. Computation and analysis of multiple structural change models. Journal of Applied Econometrics, 18, 1-22.

Bai, Z., Wong, W-K., \& Zhang, B. 2010. Multivariate linear and nonlinear causality tests. Mathematics and Computers in Simulation, 81(1), 5-17.

Bai, Z., Li, H., Wong, W-K., Zhang, B. 2011. Multivariate causality tests with simulation and application. Statistics \& Probability Letters, 81(8), 1063-1071.

Balcilar, M., Ozdemir, Z.A., 2013. The causal nexus between oil prices and equity market in the US: a regime switching model. Energy Economics 39, 271-282. 
Balcilar, M., Bekiros, S., Gupta, R., 2017a. The role of news-based uncertainty indices in predicting oil markets: a hybrid nonparametric quantile causality method. Empirical Economics, 53(3), 879-889.

Balcilar, M., Gupta, R., Miller, S.M., 2015. Regime switching model of US crude oil and stock market prices: 1859 to 2013, Energy Economics 49, 317-327.

Balcilar, M., Gupta, R., Pierdzioch, C., Wohar, M.E., 2016. Terror Attacks and Stock-Market Fluctuations: Evidence Based on a Nonparametric Causality-in-Quantiles Test for the G7 Countries. European Journal of Finance, DOI: http://dx.doi.org/10.1080/1351847X.2016.1239586.

Balcilar, M., Gupta, R., Wohar, M.E., 2017b. Common cycles and common trends in the stock and oil markets: evidence from more than 150 years of data. Energy Economics $61,72-86$.

Baumeister, C., Kilian, L., 2014. What central bankers need to know about forecasting oil prices. International Economic Review 55(3), 869-889.

Baumeister, C., Kilian, L., 2015. Forecasting the real price of oil in a changing world: a forecast combination approach. Journal of Business and Economic Statistics 33(3), $338-351$.

Baumeister, C., Guérin, P., Kilian, L., 2015. Do high-frequency financial data help forecast oil prices? The MIDAS touch at work. International Journal of Forecasting 31(2), $238-252$.

Baumeister, C., Kilian, L., Lee, T.K., 2014. Are there gains from pooling real-time oil price forecasts? Energy Economics 46, S33-S43.

Bekiros, S., Gupta, R., and Paccagnini, A. 2015. Oil Price Forecastability and Economic Uncertainty. Economics Letters, 132, 125-128.

Belloni, A., Chernozhukov, V., Chetverikov, D., Fernandez-Val, I. 2017. Conditional quantile processes based on series or many regressors. ArXiv e-prints: https://arxiv.org/abs/1105.6154.

Bharath, S. T., \& Wu, G., 2005, Long-run volatility and risk around mergers and acquisitions.

University of Michigan, Unpublished Working Paper, 2005, http://webuser.bus.umich.edu/gjwu/Papers/mergervol.pdf

Bonaccolto, G., Caporin, M., Gupta, R., Forthcoming. The dynamic impact of uncertainty in causing and forecasting the distribution of oil returns and risk. Studies in Nonlinear Dynamics and Econometrics. 
Bos, M. 2016. Oil price impact on M\&A activity in the U.S. oil and gas industry. Masters Thesis, Tilburg University.

Brock, W., Dechert, D., Scheinkman, J., and LeBaron, B. 1996. A test for independence based on the correlation dimension. Econometric Reviews, 15 197-235.

Chen, C., C. M. Cheng, R. Demirer 2017. Oil and Stock Market Momentum. Energy Economics 68, 151-159.

Diks, C. G. H. and Panchenko, V. 2005. A note on the Hiemstra-Jones test for Granger noncausality. Studies in Nonlinear Dynamics and Econometrics, 9(2), 1-7.

Diks, C. G. H. and Panchenko, V. 2006. A new statistic and practical guidelines for nonparametric Granger causality testing. Journal of Economic Dynamics and Control, 30(9-10), 1647-1669.

Dimopoulos, T., Sacchetto, S. 2017. Merger activity in industry equilibrium. Journal of Financial Economics 126, 200-226.

Elder, J., and Serletis, A. 2010. Oil Price Uncertainty. Journal of Money, Credit and Banking, 42(6), 1137-1159.

Gero G., Kamerschen, D. R. 2008. The effect of mergers on implied volatility of equity options. International Review of Financial Analysis 17 (2), 330-344.

Gupta, R., Wohar, M., 2017. Forecasting oil and stock returns with a Qual VAR using over 150 years of data. Energy Economics 62, 181-186.

Hamilton, J.D., 1983. Oil and the macroeconomy since World War II. Journal of Political Economy 91(2), 228-248.

Hamilton, J.D., 2008. Oil and the macroeconomy. In Durlauf, S., Blume, L. (eds.), New Palgrave Dictionary of Economics, 2nd edition, Palgrave McMillan Ltd.

Hamilton, J.D., 2009. Causes and consequences of the oil shock of 2007-08. Brookings Papers on Economic Activity 40(1), 215-283.

Hamilton, J.D., 2013. Historical oil shocks. In Parker, R.E., Whaples, R. (eds.), Routledge Handbook of Major Events in Economic History, New York: Routledge Taylor and Francis Group, 239-265.

Hiemstra, C. and Jones, J.D. 1994. Testing for linear and nonlinear Granger causality in the stock price-volume relation. Journal of Finance, 49(5), 1639-1664.

Hsu, K-. C-., Wright, M., Zhu, Z. 2017. What motivates merger and acquisition activities in the upstream oil \& gas sectors in the U.S.? Energy Economics 65, 240-250.

Hurvich, C.M., Tsai, C.-L. 1989. Regression and time series model selection in small samples. Biometrika 76(2), 297-307. 
Jarrell, G. A., J. A. Brickley and J. M. Netter. 1988. The Market for Corporate Control: The Empirical Evidence Since 1980. Journal of Economic Perspectives 2, 49-68.

Jayaraman, N., Madelker, G., \& Shastri, K. (1991). Market anticipation of merger activities: An empirical test. Managerial and Decision Economics, 12, 439-448.

Jensen, M. C. and R. S. Ruback. 1983. The Market for Corporate Control: The Scientific Evidence. Journal of Financial Economics 11, 5-50.

Jeong, K., Härdle, W.K., Song, S., 2012. A consistent nonparametric test for causality in quantile. Econometric Theory, 28(4), 861-887.

Kang, S.H., McIver, R., Yoon, S.-M., 2016. Modeling time-varying correlations in volatility between BRICS and commodity markets. Emerging Markets Finance and Trade 52(7), $1698-1723$.

Kang, S.H., McIver, R., Yoon, S.-M., 2017. Dynamic spillover effects among crude oil, precious metal, and agricultural commodity futures markets. Energy Economics 62, 19-32.

Kang, S.H., Yoon, S.-M., 2013. Modeling and forecasting the volatility of petroleum futures prices. Energy Economics 36, 354-362.

Langetieg, T. C., Haugen, R. A., \& Wichern, D. W. (1980). Merger and stock risk. The Journal of Financial and Quantitative Risk, 15, 689-717.

Levy, H., and Yoder, J. A. 1993. The behavior of option implied standard deviations around merger and acquisition announcements. Financial Review, 28, 261-272.

Li, Q., Racine, J., 2004. Cross-validated local linear nonparametric regression. Statistica Sinica 14(2), 485-512.

Loughran, T. and A. M. Vijh. 1997. Do Long-Term Shareholders Benefit from Corporate Acquisitions? Journal of Finance 52, 1765-1790.

Mensi, W., Beljid, M., Boubaker, A., Managi, S., 2013. Correlations and volatility spillovers across commodity and stock markets: linking energies, food, and gold. Economic Modelling 32, 15-22.

Mensi, W., Hammoudeh, S., Yoon, S.-M., 2014a. How do OPEC news and structural breaks impact returns and volatility in crude oil markets? Further evidence from a long memory process. Energy Economics 42, 343-354.

Mensi, W., Hammoudeh, S., Yoon, S.-M., 2014b. Dynamic spillovers among major energy and cereal commodity prices. Energy Economics 43, 225-243.

Mensi, W., Hammoudeh, S., Kang, S.H., 2015a. Precious metals, cereal, oil and stock market linkages and portfolio risk management: evidence from Saudi Arabia. Economic Modelling 51, 340-358. 
Mensi, W., Hammoudeh, S., Yoon, S.-M., 2015b. Structural breaks, dynamic correlations, asymmetric volatility transmission, and hedging strategies for petroleum prices and USD exchange rate. Energy Economics 48, 2015, 46-60.

Mitchell, L., and Mulherin, J. H. 1996. The impact of industry shocks on takeover and restructuring activity. Journal of Financial Economics, 41(2), 193-229.

Monge, M., and Gil-Alana, L.A. 2016. Fractional Integration and Cointegration in Merger and Acquisitions in the U.S. Petroleum Industry. Applied Economics Letters, 23(10), 701704.

Monge, M., Gil-Alana, L.A., Pérez de Gracia, F. and Carreño, I.R. 2017. Are Mergers and Acquisitions in the Petroleum Industry in U.S. affected by oil prices? Energy Sources, Part B: Economics, Planning and Policy, 12(5), 420-427.

Narayan, P.K., Gupta, R., 2015. Has oil price predicted stock returns for over a century? Energy Economics 48, 18-23.

Nishiyama, Y., Hitomi, K., Kawasaki, Y., Jeong, K., 2011. A consistent nonparametric test for nonlinear causality - Specification in time series regression. Journal of Econometrics, $165,112-127$.

Racine, J., Li, Q., 2004. Nonparametric estimation of regression functions with both categorical and continuous data. Journal of Econometrics 119(1), 99-130.

Rau, P. R. and T. Vermaelen. 1998. Glamour, Value, and the Post-Acquisition Performance of Acquiring Firms. Journal of Financial Economics 49, 223-53.

Smith, B. F., et al. 1997. Intraday volatility and trading volume after takeover announcements. Journal of Banking and Finance, 21, 337-368.

Stock, J.H. and Watson, M.W. 2003. Forecasting Output and Inflation: The Role of Asset Prices. Journal of Economic Literature 41, 788-829. 


\section{Appendix}

Table A1. GARCH-based Results of Predictability

Panel A: DEALS

Dependent Variable: RETURNS

Method: ML ARCH - Normal distribution (BFGS / Marquardt steps)

\begin{tabular}{|c|c|c|c|c|}
\hline \multicolumn{5}{|c|}{$\begin{array}{c}\text { Mean } \\
\text { Equation }\end{array}$} \\
\hline Variable & Coefficient & Std. Error & z-Statistic & Prob. \\
\hline RETURNS(-1) & 0.2432 & 0.0525 & 4.6325 & 0.0000 \\
\hline DEALS(-1) & -0.0041 & 0.0270 & -0.1845 & 0.8536 \\
\hline $\mathrm{C}$ & 0.0986 & 0.3431 & 0.2873 & 0.7739 \\
\hline \multicolumn{5}{|c|}{ Variance Equation } \\
\hline $\mathrm{C}$ & 1.4303 & 0.3837 & 3.7274 & 0.0002 \\
\hline $\operatorname{RESID}(-1)^{\wedge} 2$ & 0.3082 & 0.0442 & 6.9675 & 0.0000 \\
\hline GARCH(-1) & 0.6599 & 0.0561 & 11.773 & 0.0000 \\
\hline DEALS(-1) & 0.2201 & 0.1091 & 2.0007 & 0.0454 \\
\hline R-squared & 0.09024 & \multicolumn{2}{|c|}{ Mean dependent var } & 0.2682 \\
\hline Adjusted R-squared & 0.0863 & \multicolumn{2}{|c|}{ S.D. dependent var } & 8.1451 \\
\hline S.E. of regression & 7.7856 & \multicolumn{2}{|c|}{ Akaike info criterion } & 6.6991 \\
\hline Sum squared resid & 28125.66 & \multicolumn{2}{|c|}{ Schwarz criterion } & 6.7621 \\
\hline Log likelihood & -1557.442 & \multirow{2}{*}{\multicolumn{2}{|c|}{ Hannan-Quinn criter. }} & 6.7244 \\
\hline Durbin-Watson stat & 1.8553 & & & \\
\hline
\end{tabular}

Panel B: OIL DEALS

\begin{tabular}{lrlrr}
\hline \hline & \multicolumn{4}{c}{$\begin{array}{c}\text { Mean } \\
\text { Equation }\end{array}$} \\
\multicolumn{1}{c}{ Variable } & Coefficient & Std. Error & z-Statistic & Prob. \\
\hline \hline RETURNS(-1) & 0.24438 & 0.0521 & 4.6877 & 0.0000 \\
DEALS_OIL(-1) & -0.0097 & 0.0341 & -0.2767 & 0.7820 \\
C & 0.1206 & 0.3379 & 0.3571 & 0.7211 \\
\hline \hline \multicolumn{1}{c}{ Variance Equation } & & \\
\hline \hline RESID(-1)^2 & 1.4954 & 0.4000 & 3.7383 & 0.0002 \\
GARCH(-1) & 0.3065 & 0.0436 & 7.0258 & 0.0000 \\
DEALS_OIL(-1) & 0.6642 & 0.0554 & 11.988 & 0.0000 \\
\hline \hline R-squared & 0.2732 & 0.1439 & 1.8989 & 0.0576 \\
Adjusted R-squared & 0.0908 & Mean dependent var & 0.2682 \\
S.E. of regression & 0.0868 & S.D. dependent var & 8.1451 \\
Sum squared resid & 7.7834 & Akaike info criterion & 6.7011 \\
Log likelihood & 28109.65 & Schwarz criterion & 6.7632 \\
Durbin-Watson stat & -1557.700 & Hannan-Quinn criter. & 6.7255 \\
\hline \hline
\end{tabular}

Panel C: NONOIL DEALS 
Mean

Equation

\begin{tabular}{|c|c|c|c|c|}
\hline \\
\hline Variable & Coefficient & Std. Error & z-Statistic & Prob. \\
\hline RETURNS(-1) & 0.2411 & 0.0529 & 4.5558 & 0.0000 \\
\hline DEALS_NONOIL(-1) & 0.0139 & 0.0972 & 0.1430 & 0.8863 \\
\hline $\mathrm{C}$ & 0.0128 & 0.3174 & 0.0403 & 0.9679 \\
\hline \multicolumn{5}{|c|}{ Variance Equation } \\
\hline $\mathrm{C}$ & 1.1875 & 0.3203 & 3.7073 & 0.0002 \\
\hline $\operatorname{RESID}(-1)^{\wedge} 2$ & 0.3119 & 0.0444 & 7.0218 & 0.0000 \\
\hline GARCH(-1) & 0.6568 & 0.0536 & 12.262 & 0.0000 \\
\hline DEALS_NONOIL(-1) & 0.9705 & 0.4366 & 2.2229 & 0.0262 \\
\hline R-squared & 0.0895 & \multicolumn{2}{|c|}{ Mean dependent var } & 0.2682 \\
\hline Adjusted R-squared & 0.0855 & \multicolumn{2}{|c|}{ S.D. dependent var } & 8.1451 \\
\hline S.E. of regression & 7.7881 & \multicolumn{2}{|c|}{ Akaike info criterion } & 6.6980 \\
\hline Sum squared resid & 28149.96 & \multicolumn{2}{|c|}{ Schwarz criterion } & 6.7602 \\
\hline Log likelihood & -1556.986 & \multirow{2}{*}{\multicolumn{2}{|c|}{ Hannan-Quinn criter. }} & 6.7225 \\
\hline Durbin-Watson stat & 1.8506 & & & \\
\hline
\end{tabular}


Figure A1. Causality-in-Quantiles Test Results for Oil Volatility (GARCH(1,1) Model)

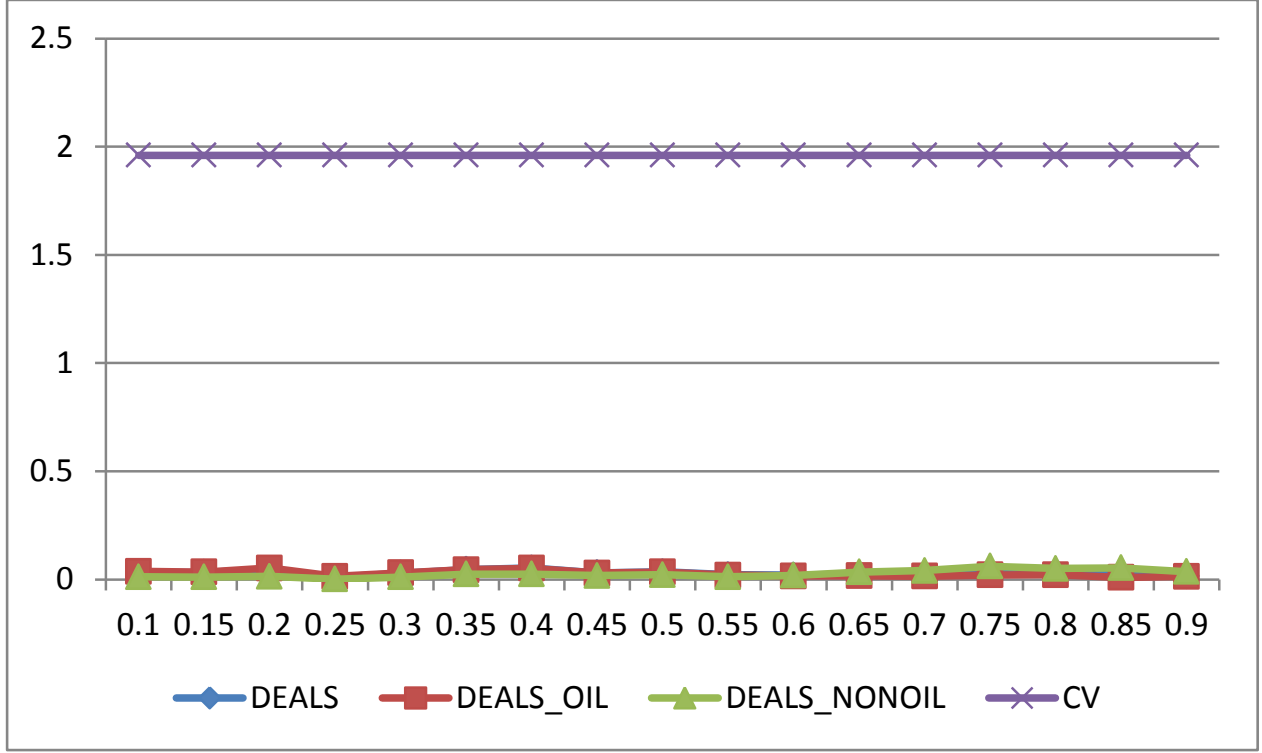

Notes: $\mathrm{CV}$ is the 5 percent critical value of 1.96 . The horizontal axis measures the various quantiles while the vertical axis captures the tests statistic value. The lines corresponding to DEALS, DEALS_OIL and DEALS_NONOIL show the rejection (nonrejection) of the null of no Granger causality from the various measures of M\&A activity measures to oil volatility derived from a $\operatorname{GARCH}(1,1)$ model at the 5 percent level, if the lines are above (below) 1.96 for a specific quantile.

Figure A2. Causality-in-Quantiles Test Results for Oil Volatility (Realized Volatility)

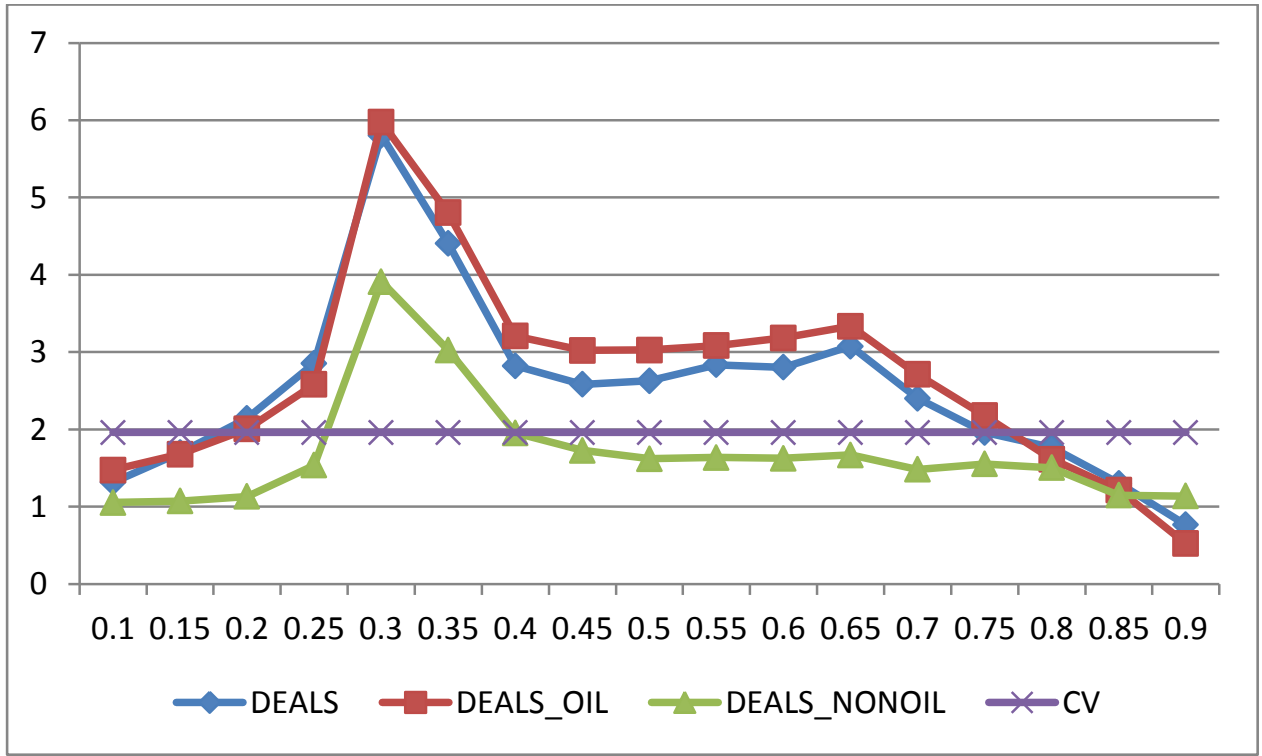

Notes: $\mathrm{CV}$ is the 5 percent critical value of 1.96. The horizontal axis measures the various quantiles while the vertical axis captures the tests statistic value. The lines corresponding to DEALS, DEALS_OIL and DEALS_NONOIL show the rejection (nonrejection) of the null of no Granger causality from the various measures of M\&A activity measures to realized volatility of oil at the 5 percent level, if the lines are above (below) 1.96 for a specific quantile. 